\title{
A Foundation for the Study of Behavior Change Support Systems
}

\author{
Harri Oinas-Kukkonen \\ University of Oulu, Dept. Information Processing Science \\ Rakentajantie 3, 90570 Oulu, Finland \\ Tel: +358-8-553-1900 \\ Fax: +358-8-553-1890 \\ Harri.Oinas-Kukkonen@oulu.fi
}

\begin{abstract}
The emerging ambient persuasive technology looks very promising for many areas of personal and ubiquitous computing. Persuasive applications aim at changing human attitudes or behavior through the power of software designs. This theory-creating article suggests the concept of a behavior change support system (BCSS), whether web-based, mobile, ubiquitous or more traditional information system to be treated as the core of research into persuasion, influence, nudge and coercion. This article provides a foundation for studying BCSSs, in which the key constructs are the O/C matrix and the PSD model. It will (1) introduce the archetypes of behavior change via BCSSs, (2) describe the design process for building persuasive BCSSs, and (3) exemplify research into BCSSs through the domain of health interventions. Recognizing the themes put forward in this article will help leverage the full potential of computing for producing behavioral changes.
\end{abstract}

Keywords: Behavior change support systems, socio-technical system, persuasive technology, behavioral outcomes, psychological outcomes, behavioral change.

\section{Introduction}

The emergence of social web and mobile applications to create, access, and share information in new ways has opened up opportunities for also developing new kinds of information systems for influencing users. For instance, one of the most prominent areas for future healthcare improvement is the role of the web in fostering improved health and healthier lifestyles [1]. Researchers have reported positive results in areas such as the management of smoking cessation, hazardous drinking, obesity, diabetes, asthma, tinnitus, stress, anxiety and depression, complicated grief, and insomnia [2]. Other application areas range from persuading users to adopt greener energy behaviors [3] to helping them to stick into proper exercise behaviors [4].

The contemporary and future web will keep opening up a myriad of opportunities for building various kinds of software applications targeted for behavioral change. For this reason, both software developers and the general audience should be aware of the various ways of and the approaches to how people may be, are being, and will be influenced through the information technology designs [5]. In more general, computer science as a field has the responsibility of educating the general audience about the pros and cons of people's behaviors being influenced by information systems, whereas web and other software developers must realize that they exercise enormous power over the users because their designs always influence them in one way or another, whether they intend them to or not.

Scientific research urges for proper theoretical frameworks. Theories related to user attitudes and behaviors are many [e.g., see 6, 7]. However, there is much less attitude/behavior changespecific theories; those that do exist include the Self-Efficacy Theory [8], the Social Cognitive Theory [9], and Elaboration Likelihood Model [10]. All of these provide a solid theoretical starting point to carry out research on behavioral changes. Yet, what these theories and therefore many of contemporary studies lack for are descriptions of the software systems in terms of their structure, content, and functionality, and in many cases even about their intent [11-14]. We suggest here that in addition to rigor theoretical background and proper methods for measuring the actual behavioral changes two important steps (in between theory and measurement) must be taken, namely analysis of the intent and analysis of the persuasive potential of the system.

This article is conceptual and theory-creating by its nature. It will suggest two important prerequisites before actually being able to measure and demonstrate a behavior change being caused by an IT artifact. The article is structured as follows: Section 2 will describe theories related to behavior change. Section 3 will define and discuss the concept of a behavior change 
support system (BCSS) as a key construct for research into persuasion, influence, nudge and coercion, suggesting the O/C matrix as a means for analyzing the intent of a BCSS. Section 4 will position persuasion as the central approach for achieving behavior change via BCSS, suggesting the PSD model as a means for analyzing the persuasive potential of the system. Section 5 will exemplify research into BCSS through the domain of health interventions. Section 6 will discuss the implications and future research directions of the suggested approach. In general, this article lays ground for the new frontier of research on BCSSs.

\section{Theoretical background}

The study of users' attitudes and behavior has a long history in computer science [15]. Prominent theories related to user attitudes and behaviors include, for instance, the Theory of Reasoned Action [6] and the Theory of Planned Behavior [7]. Lessons have been drawn especially from social psychology and cognitive psychology, and even some original computer science theories have been developed, such as the Technology Acceptance Model [16] and the Unified Theory of Use and Acceptance of Technology [17]. These theories are useful for understanding behavioral intentions and control related to information systems and their use, and some of them are relatively well-known among computer scientists. Besides these attitude and behavior-related theories, there are some theories that specifically discuss the change of attitudes or behaviors, such as the SelfEfficacy Theory [8], the Social Cognitive Theory [9], the Elaboration Likelihood Model [10], the Cognitive Dissonance Theory [18], and the Goal Setting Theory [19]; even a few extensions of these theories into the computer science field do exist such as the Computer Self-Efficacy [20]. These change-specific theories are not very well-known among computer science researchers, however. For a summary of behavior change related theories, see Table 1.

Table 1 Behavior change related theories

\begin{tabular}{|c|c|}
\hline Theory of Reasoned Action & $\begin{array}{l}\text { Individual behavior is determined by behavioral intentions, i.e., an individual's } \\
\text { attitude toward the behavior and subjective norms about the behavior [6] }\end{array}$ \\
\hline Theory of Planned Behavior & $\begin{array}{l}\text { Individual's perception of the ease with which the behavior can be performed, } \\
\text { i.e., behavioral control, influences individual's behaviors [7] }\end{array}$ \\
\hline Technology Acceptance Model & $\begin{array}{l}\text { Perceived usefulness and perceived ease of use determine an individual's } \\
\text { intention to use a system, which leads into actual system use; perceived } \\
\text { ease of use impacts perceived usefulness; assumes that actors are free to } \\
\text { act without limitations when they just have an intention to act; based on } \\
\text { Theory of Reasoned Action [16] }\end{array}$ \\
\hline $\begin{array}{l}\text { Unified Theory of Acceptance } \\
\text { and Use of Technology }\end{array}$ & $\begin{array}{l}\text { Performance expectancy, effort expectancy, social influence, and facilitating } \\
\text { conditions determine the usage intention and usage behavior, whereas } \\
\text { gender, age, experience, and voluntariness of use moderate this impact; } \\
\text { extended from Technology Acceptance Model [17] }\end{array}$ \\
\hline Self-Efficacy Theory & $\begin{array}{l}\text { Individuals who perceive themselves as capable of taking action also do take } \\
\text { action; strengthening the sense of efficacy happens through vicarious } \\
\text { experiences, social models, social persuasion, and reducing people's stress } \\
\text { reactions and altering their negative emotional proclivities and } \\
\text { misinterpretations of their physical states }[8,21]\end{array}$ \\
\hline Social Cognitive Theory & $\begin{array}{l}\text { Observing others performing a behavior influences the perceptions of } \\
\text { individual's own ability to perform the behavior, i.e. self-efficacy, and the } \\
\text { perceived expected outcomes [9] }\end{array}$ \\
\hline Elaboration Likelihood Model & $\begin{array}{l}\text { Central and peripheral routes are key routes for persuasion; central route is } \\
\text { used when information processing is based upon critical thinking; peripheral } \\
\text { route is based on rules of thumb; change via central route is more enduring, } \\
\text { resistant and predictive of behavior [10] }\end{array}$ \\
\hline Cognitive Dissonance Theory & $\begin{array}{l}\text { Individuals seek consistency among their cognitions such as beliefs and } \\
\text { opinions; inconsistency between attitudes or behaviors creates dissonance } \\
\text { that needs to be eliminated [18] }\end{array}$ \\
\hline Goal Setting Theory & $\begin{array}{l}\text { Goals affect performance through directing attention and effort, energizing, } \\
\text { persistence, and by leading to arousal and/or use of task-relevant knowledge } \\
\text { and strategies; the highest goals produce the highest levels of effort and } \\
\text { performance; specific, difficult goals consistently lead to higher performance } \\
\text { than urging people to do their best; when goals are self-set, people with high } \\
\text { self-efficacy set higher goals than people with lower self-efficacy; people with } \\
\text { high self-efficacy are more committed to the assigned goals and and to } \\
\text { responding more positively to negative feedback [19] }\end{array}$ \\
\hline Computer Self-Efficacy & $\begin{array}{l}\text { Computer self-efficacy means individual's judgment of one's capabilities to } \\
\text { use computers for both task performance and computer performance; } \\
\text { anxiety, innovativeness, task characteristics, prior performance, and } \\
\text { perceived effort play a role; based on Self-Efficacy Theory [20] }\end{array}$ \\
\hline
\end{tabular}


There are also specific theoretical models within application domains; for instance, models that have stemmed from the healthcare field and which have received large attention in health behavior change include the Health Belief Model [22, 23] and the Transtheoretical Model [24, 25]. Some world-renowned scholars, such as Fishbein [27] and Bandura [28], have recently also been working in the area. For instance, Fishbein's [27] integrative model combines variables derived from the Health Belief Model, the Theory of Reasoned Action, and Social Cognitive Theory. According to this model, an individual is more likely to engage in a target health behavior if one's intention to perform is strong, one has the skills and abilities to perform it, and one does not encounter barriers to engaging in the behavior. Those who intend to perform a specific behavior but are unable to do so are very different from those who have no intention and lack motivation. Theoretical frameworks specifically developed for helping to understand software users' health behavior changes have also been suggested, such as the eHealth Behavior Management Model [26].

All of these behavior change related theories and models no matter whether they are healthspecific, software user focused or more general ones, however, lack in their understanding and descriptive power for the potential uses and benefits and in particular for the information system characteristics. For this reason, sharper conceptual-theoretical means for carrying out research on information systems focused on behavioral change are needed.

\section{Analysis of the intended outcome/change}

Even if the web and other information technologies are often considered as just tools to accomplish goals, they are actually never neutral; rather, they are 'always on' [5]. This means that people are constantly being persuaded in a similar manner to how teachers persuade students in schools, and there is nothing bad in this in itself, of course. To put it simply, information technology always influences people's attitudes and behaviors in one way or another. In some cases, the influence may even be an unintentional side effect of the design. Thus, software designers but also the general audience should be well aware of the various ways and approaches how people may be, are being, and will be influenced through IT design.

There is a plethora of applications that can be developed with the purpose of behavioral change. ${ }^{1}$ For these reasons, it is important to define and adopt into use the concept of a behavior change support system. A BCSS is defined here as follows:

A behavior change support system (BCSS) is a socio-technical information system with psychological and behavioral outcomes designed to form, alter or reinforce attitudes, behaviors or an act of complying without using coercion or deception.

In this article, three potential, successful voluntary outcomes are the formation, alteration or reinforcement of attitudes, behaviors or complying. Based on the intended outcomes and the types of change a framework for helping design and research, the O/C matrix, is suggested here. See Table 2. A forming outcome (F-Outcome) means the formulation of a pattern for a situation where one did not exist beforehand, e.g., abstaining from substance abuse. An altering outcome (AOutcome) means changes in a person's response to an issue, e.g., increasing the level of exercise, decreasing the amount of drinking, or stopping smoking. An increase or decrease on a behavior can be related to frequency, intensity or duration of the behavior [70]. Stopping a behavior in practice leads often into a situation in which also forming a new behavior (F-Outcome) is initiated. A reinforcing outcome (R-Outcome) means the reinforcement of current attitudes or behaviors, making them more resistant to change. Thus, R-outcome should be treated as change as well, even if its magnitude may be relatively small or it would not suggest a transformation from one position to another position. In many cases a F-outcome may have a higher likelihood of success than communication that aims at A-Outcome, whereas reinforced beliefs and behavior (R-Outcome) become the most resistant ones as time goes by [29]. Naturally, users' motivational level and goal setting [19] play a big role in trying to achieve any of the F-, A- or R-outcomes.

1 It should be noted that even if we speak about behavioral changes, we do not posit a behaviorist or any mechanistic psychological view towards human beings. End-users may use these applications to support achieving their goals, maintaining a constructivist view (cf., the field of education) towards human behavior. 
Table 2 Outcome/Change design matrix

\begin{tabular}{|l|l|l|l|}
\hline & C-Change & B-Change & A-Change \\
\hline F-Outcome & $\begin{array}{l}\text { Forming an act of } \\
\text { complying (F/C) }\end{array}$ & Forming a behavior (F/B) & Forming an attitude (F/A) \\
\hline A-Outcome & $\begin{array}{l}\text { Altering an act of } \\
\text { complying (A/C) }\end{array}$ & Altering a behavior (A/B) & Altering an attitude (A/A) \\
\hline R-Outcome & $\begin{array}{l}\text { Reinforcing an act of } \\
\text { complying (R/C) }\end{array}$ & $\begin{array}{l}\text { Reinforcing a behavior } \\
(\mathrm{R} / \mathrm{B})\end{array}$ & $\begin{array}{l}\text { Reinforcing an attitude } \\
(\mathrm{R} / \mathrm{A})\end{array}$ \\
\hline
\end{tabular}

In the abovementioned definition of the BCSS, we divide changes into three categories, namely a change in an act of complying, a behavior change or an attitude change. ${ }^{2}$ Respectively, these archetypes of a behavioral change may be called C-, B-, and A-Change, in ascending order of difficulty.

With a C-Change, the goal of the behavioral change is simply to make sure that the end-user complies with the requests of the system. For instance, the goal of a healthcare application may be to guarantee that its users take their daily blood pressure medication. The users may or may not have the proper motivation for doing so, but, nevertheless, the key in this approach is to provide triggers for the user to take action and to comply with the requests of the application. Yet, first achieving a C-Change may help to achieve a B-Change later. It should also be noted that a myriad of software applications that have been created for purposes other than a behavioral change per se utilize, in the micro scale, the same design principles and techniques as systems supporting CChange. In other words, they "nudge" the user through user interface, social or other cues.

The goal of systems supporting a $B$-Change is to elicit a more enduring change than simple compliance once or a few times. Naturally, a one-time behavior change may be achieved more easily, whereas long-term behavior change (not to even speak about a permanent behavior change) is much more difficult to achieve. Schedule for performing a desired behavior also plays a role in behavior change, especially with B-Change. One-time behavior may lead to an ongoing obligation or cost, a behavior may be exercised for a period of time, or a behavior may be repeated on predictable schedule [70].

The goal of systems supporting an A-Change is to influence the end-users' attitudes rather than behavior only. An attitude change that directs behavior may be the most difficult type of change to achieve but we maintain that change-in-full occurs only when attitude change takes place, and that a sustainable B-Change happens only through an A-Change. In some cases, behavior change support systems should aim bolstering both an A-Change and a B-Change simultaneously. This is particularly important in areas such as providing support for overcoming addictive behaviors, where users in spite of high motivation and proper attitudes may lack the skills to put their knowledge and attitudes into practice (a B-Change is needed), but at the same time their selfefficacy may need further strengthening (an A-Change is needed). ${ }^{3}$

By definition, different goals and often also different strategies will be needed for applications supporting A-, B, or C-changes as well as for targeting at F-, A- and R-Outcomes. When researching or developing a BCSS, it should be carefully considered which of these nine outcome/change cells an application is aimed at in order to be better equipped to pinpoint the research results and/or to direct design efforts. The context for change may be remarkably different between the different cells in the matrix. For instance, helping a schoolchild to adopt a healthy lifestyle by deciding not to start smoking $(\mathrm{F} / \mathrm{B})$, encouraging a teenager to continue to stay away from smoking despite of potential peer pressure $(\mathrm{R} / \mathrm{B})$, and motivating someone that currently smokes to stop smoking (A/B) would require in most cases very different approaches. Yet, the description of the intended outcome/change is sometimes lacking, not only from applications, but even from scientific articles specifically focusing on interventions for behavioral change. Furthermore, how to move from one cell to another seems to be a neglected area in BCSS research.

In overall, what distinguishes research into BCSSs from research into other information systems is that BCSSs are inherently transformative, deliberately attempting to cause a cognitive and/or an

2 For the sake of simplicity, we use the term "behavior" change rather than "behavioral" change even if the BCSS covers all three behavioral change types.

3 Tørning and Oinas-Kukkonen [30] report some interesting findings about the current state of research on BCSSs. For instance, thus far there has been much more research on C- and B-Change than on A-Change; only about $16 \%$ of studies in their analysis regarding the different types of change addressed A-Change. 
emotional change in the mental state of a user to transform the user's current state into another planned state and to cause a corresponding change in the user's behaviors. In implementing these systems many kinds of issues have to be taken into account. Some of the issues are technical, but many of them are user-related, social and in some situations they may also relate to organizations, cultures or society; they may relate to the quality and content of information, personal goals set by the end-users, and social environments, among other issues. The development of BCSSs can not be narrowed down to being just a user interface issue either. Indeed, a variety of topics beyond human-computer interaction and computer-mediated communication, such as approaches, methodologies, processes and tools to develop such systems and ways for studying the organizational, social, and end-user impacts of them need attention. Technologically, the research may relate to socio-technical platforms, systems, services or applications, or the software features in them, developed for the purpose of achieving behavior change; these all denote different approaches. In many cases, the BCSSs must be available 24/7, they have to address global and cultural issues with a multitude of standards, habits, and beliefs, and they have to be adaptable into a variety of business models.

\section{Analysis of the persuasive potential}

Many forms of attempted influence do exist, including deception and coercion as well as monetary inducements. These other means may be very effective vehicles for producing behavioral changes, but the voluntary nature of behaviour change support systems exclude, by definition, deception and coercion [cf. 31]. For instance, pop-up windows that always lead to the same outcome (e.g. downloading a file) whether you choose "ok" or "cancel" can be considered both deceptive and coercive. An ideal BCSS persuades its users to adopt the target behavior. The role of inducements, i.e., exchanges of money, goods, or services for actions by the person being influenced, is a more complicated issue. Yet, in its purest form persuasion excludes at least monetary inducements; persuasion relies on the power of verbal and non-verbal symbols and allows people's voluntary participation in the persuasion process [32].

Persuasive design and technology has received growing interest among researchers for a little over a decade now [cf. 33]. ${ }^{4}$ Fogg's seminal book [36] was the first conceptualization suggested for software designers, stating that information technology may play the role of a tool, a medium, or a social actor for its users, whereas Bogost [37] proposed an approach to developing persuasive games. More recently, elaborate conceptual and design frameworks for on and off-the-web information systems have been suggested, such as the Persuasive Systems Design model [38, 5]. A wide variety of persuasive applications have been developed, such as an easy-to-use password creation mechanism to help create stronger passwords [39], an interactive picture frame for adopting better sitting habits while working at the computer [40], a ubiquitous sensor-based kitchen application for improving home cooking by providing calorie awareness regarding the food ingredients used in the meals prepared [41], and a personal health information system to influence the health behaviors of rural women in undeveloped countries through offering them information for increasing their awareness about menses and maternal health [42]. Recently, one of the major development trends has been the persuasion patterns of social network based information systems, in particular in conjunction with Facebook [43] and Twitter [44].

Indeed, the key element in voluntary use of a BCSS is persuasion. Thus, behavior change support systems are, in essence, persuasive systems. They may utilize either computer-mediated or computer-human persuasion [45]. Computer-mediated persuasion means that people are persuading others through computers, e.g., e-mail, instant messages, or social network systems. Some patterns of interaction similar to social communication may be utilized also in computerhuman persuasion, even if the web cannot communicate in the same way as humans do. However, in the case of BCSSs there always are stakeholders who have the intention of influencing someone's attitudes or behavior, as computers do not have intentions of their own. These stakeholders are those who create or produce BCSSs, those who give access to or distribute them to others, or the very person adopting or using such a system [36]. BCSSs emphasize - but are not

4 Persuasive technology can be described as an interdisciplinary field of research, whereas a BCSS is an object of study within the field. Affective computing [34] may be recognized as a sister-field of persuasive technology, or perhaps from the persuasive viewpoint as a sub-field of it, which more directly focuses on the emotions systems evoke. Sharp criticism of persuasive technology has been posed by Atkinson [35]. 
limited to - autogenous approaches in which people use information technology to change their own attitudes or behaviors through building upon their own motivation or goal. Beyond being a special case of a persuasive system, a BCSS also has characteristics of its own. A BCSS places more emphasis on the actual outcome than a persuasive system, which, even if its developers were interested in the outcomes as well, in most cases emphasizes more the persuader's intent than measuring the actual outcome. Another special characteristic of BCSSs is that they request a much stronger emphasis on positive user experience and stickiness to motivate users to engage with them regularly over an extended period of time.

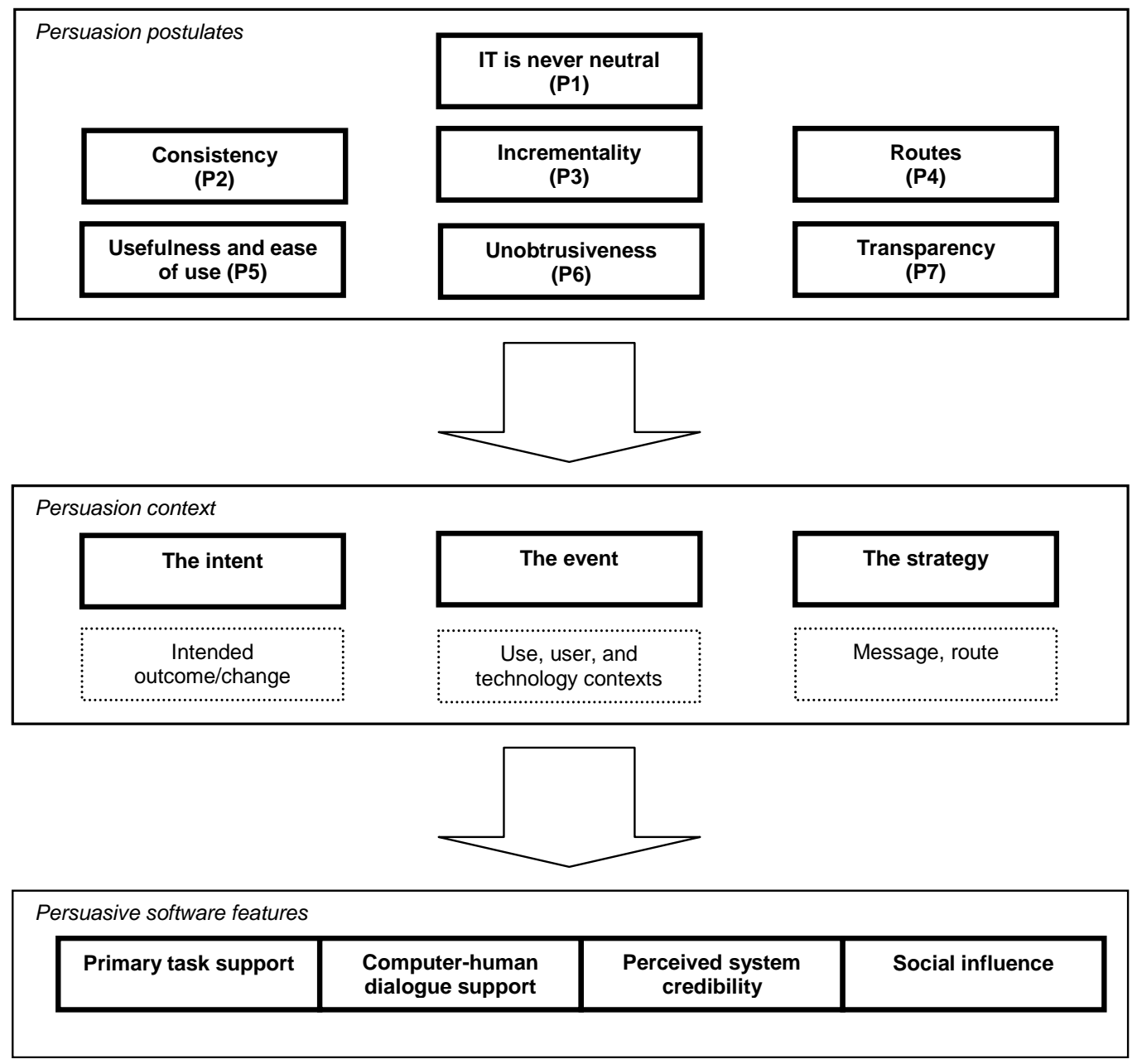

Fig 1 The persuasive systems design process (modified from [5])

The Persuasive Systems Design model $[38,5]$, or more briefly the PSD, is the state of the art vehicle for designing and evaluating BCSSs [46-52]. See Fig. 1. The PSD model defines seven postulates or core issues that are common for all BCSSs. Philosophically and as already stated above, information technology is never neutral but rather it always influences its user(s) in one way or another (P1). Moreover, building BCSSs requires insight from software and information systems design as well as from psychology. Lessons learned from psychology include that (P2) people like their views about the world to be organized and consistent, (P3) persuasion is often incremental, and (P4) the direct and indirect routes are key persuasion strategies. ${ }^{5}$ Important software design requirements to be always kept in mind when developing BCSSs are that: (P5) behavior change support systems should be both useful and easy to use, (P6) persuasion through behavior change support systems must always be unobtrusive to a user's primary tasks, and (P7) persuasion through behavior change support systems should always be transparent. Quite understandably, if a system is useless or difficult to use, or it is not well-mapped with a user's first and foremost interests and needs, it is unlikely that it could be very persuasive. The transparency requirement emphasizes the need for revealing the designer bias behind a BCSS.

\footnotetext{
5 Psychological theories tend to differ between each other in their views to and emphasis of P2, P3 and P4.
} 


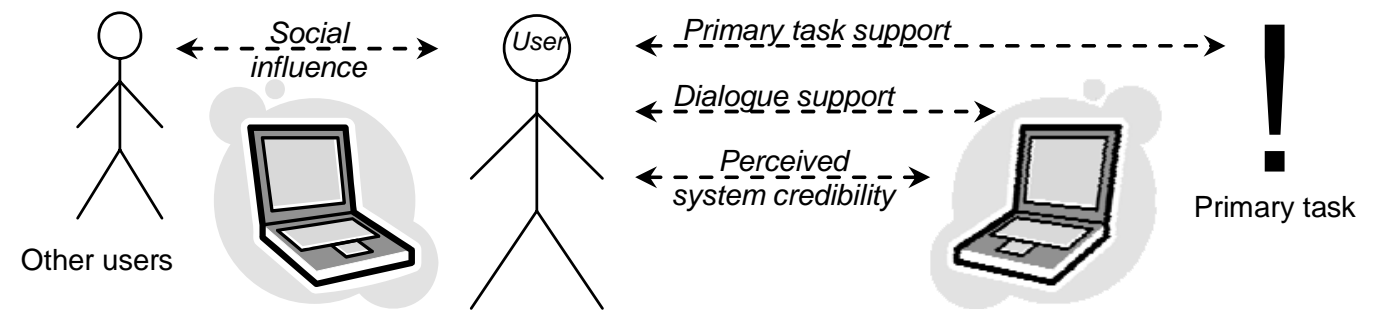

Fig. 2 Persuasive software feature categories in BCSSs

According to the PSD model, the next step needed after obtaining a deeper understanding of persuasion in general is a careful analysis of the persuasion context (the intent, event, and strategy of persuasion) to discern opportune and/or inopportune moments for delivering the message(s). This is where the intended outcome/change is analyzed via the O/C matrix; in a similar manner, the message and the route that will be used to deliver the message, the user and use situation modeling, and many technological issues must be resolved.

The PSD model also defines a wide range of software features ${ }^{6}$ for BCSSs and describes them under four categories, namely primary task support, computer-human dialogue support, perceived system credibility, and social influence. See Fig. 2. The design principles of the primary task category, e.g. tailoring, tunneling, and self-monitoring, focus on supporting the carrying out of the user's primary activities; design principles related to computer-human dialogue, e.g. verbal praise, timely suggestions, virtual rewards, and real-time reminders, aim at easing the achievement of the goal(s) set for using the BCSS; the perceived system credibility design principles relate to how to design a system so that it is more believable and thereby more persuasive, e.g., by showing expertise or referring to authority and endorsements; and the design principles in the social influence category describe how to design the system so that it motivates users by leveraging social behaviors, e.g., via social learning, comparison and facilitation. The PSD model does not, however, put forward a claim that all possible software features should always be implemented into a BCSS. It should be noted that in some cases increased elaboration may lead into decreased overall persuasiveness [cf. 10]. It is also important to note that many of the aspects in developing BCSSs are general software design and content creation issues rather than specific to BCSSs only. These include, for instance, lack of errors, high information quality, attractiveness, responsiveness, ease of access, and high overall usability.

Table 3 Examples of BCSS studies related to the PSD model

\begin{tabular}{|l|l|}
\hline Davis [56] & $\begin{array}{l}\text { Studied the ethical implications of persuasive systems in relation to participatory design } \\
\text { methods; utilized the PSD to introduce persuasive features for the participants in their } \\
\text { "inspiration card workshops" }\end{array}$ \\
\hline Harjumaa et al. [4] & $\begin{array}{l}\text { Qualitative study in exercise domain by using heart rate monitors; 12 participants for a } \\
\text { period of three months; the system was found to incorporate ten distinct persuasive } \\
\text { features; some features influenced most users whereas some had effect only on some of } \\
\text { them; the most motivating features were found to be the weekly goals, tracking } \\
\text { performance during and after exercising and on a weekly basis, and the adoption of a } \\
\text { social role; short-term verbal system feedback via praise and rewards appeared to be } \\
\text { powerful in some specific cases }\end{array}$ \\
\hline Kelders et al. [55] & $\begin{array}{l}\text { Systematic review of the persuasive features in BCSSs for weight control and weight- } \\
\text { loss; findings suggest that with web-based interventions most attention thus far has been } \\
\text { given to the primary task support, whereas dialogue support and social support appear } \\
\text { to be neglected; suggests that persuasive systems can increase adherence and lower } \\
\text { attrition rates in e-health studies }\end{array}$ \\
\hline $\begin{array}{l}\text { Lehto and Oinas- } \\
\text { Kukkonen [11] }\end{array}$ & $\begin{array}{l}\text { Qualitative evaluation of the persuasiveness of six Web-based alcohol interventions; } \\
\text { despite of the intented B-Change the systems were not found to be very persuasive; they } \\
\text { provided relatively poor primary task support (surprisingly little use of tailoring); } \\
\text { successful in trustworthiness, expertise, and surface credibility; notable differences in } \\
\text { online social influence; the systems seem to be targeted for too broad an audience }\end{array}$ \\
\hline Qualitative evaluation of persuasive features on weight loss websites; the evaluated \\
\hline
\end{tabular}

${ }^{6}$ Many of these persuasive features originate from Fogg [36]. 


\begin{tabular}{|c|c|}
\hline Kukkonen [57] & $\begin{array}{l}\text { systems were found to provide relatively good primary task support and strong social } \\
\text { support; weaknesses in both dialogue and credibility support; the overall persuasiveness } \\
\text { relativel low; improvements suggested }\end{array}$ \\
\hline $\begin{array}{l}\text { Lehto and Oinas- } \\
\text { Kukkonen [14] }\end{array}$ & $\begin{array}{l}\text { Systematic review of web-based interventions for substance use; randomized controlled } \\
\text { trials published during 2004-2009; interpretive approach for persuasive features; primary } \\
\text { task support was reported relatively widely in the reviewed studies (reduction, self- } \\
\text { monitoring, simulation, and personalization being the most used features); leveraging } \\
\text { reminders was the most common way to enhance the user-system dialogue; credibility } \\
\text { support was at a relatively high level; the prevalence of social support was encouraging }\end{array}$ \\
\hline Räisänen et al. [53] & $\begin{array}{l}\text { Applied the PSD model for evaluating the persuasiveness of software design } \\
\text { specifications for a Internet tablet under development; the model was found to fit well for } \\
\text { evaluating design specifications; suggests also that practitioners with no theoretical } \\
\text { background on the PSD can apply the model to increase the persuasiveness of the } \\
\text { systems they design; exemplifies how to use the PSD model in relation with a specific } \\
\text { theory; the need for specific heuristics for evaluating persuasive features recognized }\end{array}$ \\
\hline $\begin{array}{l}\text { Segerståhl et al. } \\
\text { [54] }\end{array}$ & $\begin{array}{l}\text { Qualitative field study about situations where persuasive features do not function as } \\
\text { expected; weight loss utilized as an problem domain; PSD used to recognize persuasive } \\
\text { features; the pitfalls discovered linked with manual logging of eating and exercise } \\
\text { behaviors, provision of suggestions and source credibility regarding social facilitation }\end{array}$ \\
\hline Stibe et al. [44] & $\begin{array}{l}\text { Quantitative survey of Twitter users in Latvia; addressed the incremental persuasion } \\
\text { postulate; focused on persuasion patterns in social networks and microblogging; } \\
\text { suggests patterns for step-by-step B- and A-changes }\end{array}$ \\
\hline $\begin{array}{l}\text { Tørning and Oinas- } \\
\text { Kukkonen [30] }\end{array}$ & $\begin{array}{l}\text { Review of research on persuasive systems; most research thus far has been } \\
\text { experimental; } 84.4 \% \text { has addressed C- or B-change; the most utilized features have } \\
\text { been tailoring, tunneling, reduction, and self-monitoring (representing the primary task } \\
\text { category), suggestion (for supporting human-computer dialogue), surface credibility (in } \\
\text { support of perceived system credibility), and social comparison, normative influence, and } \\
\text { social learning (relating to social influence); surprisingly, ethical considerations have } \\
\text { remained largely unaddressed }\end{array}$ \\
\hline Wiafe et al. [58] & $\begin{array}{l}\text { Extended the PSD model for helping to select appropriate persuasive techniques } \\
\text { depending on the nature of users or use over time; presents a model between attitude } \\
\text { towards behavior, attitude towards change or maintaining a change, and current } \\
\text { behavior; distinguishes variable levels in a user's cognitive state }\end{array}$ \\
\hline Yetim [59] & $\begin{array}{l}\text { Critically uses and evaluates the PSD model, proposing a set of questions for pragmatic, } \\
\text { ethical and moral discourses for the design and use of persuasive systems; based on } \\
\text { argumentation research; emphasizes value-sensitive participatory design }\end{array}$ \\
\hline
\end{tabular}

The applicability of the PSD model is wide. The model can be used in a variety of settings ranging from evaluating software specifications in the early stages of systems development [53] to studying full-fledged commercial applications [54] to analyzing research literature in a given problem domain $[14,55]$. The PSD model is a highly useful tool for researchers and designers, but of course it can't guarantee the success of any BCSS. For examples of studies explicitly using the PSD model, see Table 3.

\section{Example: Health BCSS}

The research into healthcare information and management systems thus far has mostly focused on electronic medical records and health information libraries with less attention to tools for patients' behavioral change [60; for the latter, see e.g. 61, 62], and yet one of the most prominent areas for future healthcare improvement has been suggested to be the role of information systems in fostering improved health and healthier lifestyles [1]. Current health behavior change support systems still are typically behavioral treatments operationalized and transformed for web delivery with the goal of symptom improvement [63], but they can also be delivered via SMS, social networking systems or by other state-of-art technological means. In fact, there is already a plethora of health interventions available via mobile devices. Health BCSSs have been reported to produce positive results in areas such as management of smoking cessation, hazardous drinking, obesity, diabetes, asthma, tinnitus, stress, anxiety and depression, complicated grief, and insomnia [2]. 
Naturally, the research has not found these interventions always to play the biggest role in the change process, but nevertheless the majority of the published works have found improved knowledge and positive psychological, behavioral, or clinical outcomes [64]. At the same time, room for significant improvements still exists. For instance, $80 \%$ of the smoking cessation sites failed to cover one or more key components of recommended cessation treatment guidelines and the true utilization of the web's most potential features was generally ignored [65]; in many cases these software applications also made very low utilization of health behavior change theories [66].

In medicine and psychology, it is randomized controlled trials (RCT) that are appraised and that receive most of the attention. The elevated position of RCTs being "the king” is only natural, because via RCTs it is possible to actually measure and demonstrate a change in a behavior. Previously, there were relatively few RCTs studying health behavior change support systems. However, in the last decade things have changed and more and more randomized controlled trials about health BCSSs have been published. Portnoy et al. [67] conducted a meta-analysis of RCTs on efficacy, improved antecedents of health behavior and general health maintenance from studies carried out between 1988 and 2007. They discovered that several characteristics moderated the improved psychological (knowledge, attitudes, and intentions) and behavioral outcomes (e.g. nutrition, substance use). Improved results were achieved at the first milestone, i.e. at first posttreatment assessment. The researchers suggested that longer research periods would be needed in further research. From the 75 RCTs Portnoy et al. [67] studied, 73\% used at least one theory, and $36 \%$ used more than one theory. In terms of problem domain, $37 \%$ of the studies were related to overweight/obesity and $23 \%$ on alcohol and/or drugs. The data was often relatively biased, since in $59 \%$ of the studies the participants came from a community/clinical setting, and in 38\% they were from a school/university setting. A median RCT was found to provide three intervention sessions of 21 minutes each (with a single theory), 11 intervention sessions of 45 minutes each (when multiple theories were used), or 42 intervention sessions of 6 minutes each (when electronic peer support was used - however, there were only two of these kinds of systems in the data). According to the study, $65 \%$ of the health BCSSs were tailored. Out of these, $18 \%$ were tailored towards a group, $88 \%$ included a motivational component, and $89 \%$ included skill training. They found evidence of successful support on six widely-varying behaviors, including substance use, which is often resistant to change even with therapist-facilitated interventions. Their explanation for this surprisingly positive result is that health BCSSs may help organize previously latent motivation and behavioral skills.

Portnoy et al. [67] sugggest that one of the challenges in health BCSS research is that providing an individual with any active intervention content is likely to lead to some change in the psychological antecedents and/or behavior. Moreover, in many cases any active comparison condition (including placebo) may decrease the difference between the treatment and control groups. They also found that older participants were less efficacious for increasing knowledge, attitudes and self-efficacy. This may be a result of the selected sets of participants, which, to a relatively large extent, were student-based. Quite surprisingly, the inclusion of motivational components, such as cost-benefit analysis for a behavior, seemed to weaken the impact of the health BCSS on A-change and social norms. This is a counter-intuitive finding, and needs more research. They found no support for the impact of tailoring activities (whether at individual or group level) on the change, which also offers room for further research.

According to Ritterband et al. [63], the web may make a significant difference, particularly in C-Change, even if studying the C-Change may also become more problematic via the web because of limited supervision and control. Nevertheless, the web-based health BCSSs may be highly engaging and personalized, and they may, for instance, offer information in the form of quizzes, games and case reports - something that is a relatively new idea in the field of health information systems. It would be important to assess the impact of these both individually and as a part of a larger whole from multiple viewpoints (e.g. feasibility, usability, and efficacy). According to Ritterband et al. [63], more research on the web's ability to elicit actual behavioral changes, more methodologically rigorous clinical studies, and a theoretical model for behavioral change are still badly needed. These will provide a new platform from which research on health behavior change support systems can be conducted.

One of the greatest challenges for the BCSSs is that physicians generally think that information systems have little relevance to their clinical work with patients. Moreover, most of the research questions tackled in scientific publications so far have focused on problems that are relatively easy to solve or at least which are easily measurable. In future work, more serious problems should be tackled and a more complex view towards the durability of the behavioral change should be 
adopted. Currently, most of the researchers involved with systems supporting health behavioral change and having their background in the healthcare field seem to be interested in either CChange or B-Change. Most of those computer-human interaction researchers who are involved in the area of behavioral change seem to focus on C-Change, too, whereas social psychologists working in the area of health BCSSs constitute the largest single group of researchers who are interested also in A-Change. In the future, more research should be devoted to A-Change rather than C-Change or B-Change only.

Even if Portnoy et al. [67] and others have found evidence for the success of health BCSSs, there is a major drawback in most of the published works so far. The support systems are almost always very poorly described [13, 14]. All too often, no details about the system are provided at all. A major reason for this deficiency is that most of this type of research has been published by physicians and medical experts without consulting the computer scientists. Moreover, many larger health organizations typically prefer to create their own materials, and they are only now beginning to understand that custom web sites that go beyond their pamphlets require significant expertise, effort, and expense [2]. Knowledge delivery does not automatically equal health behavior change. Much more than just the provision of information is needed. Duffett-Leger et al. [68] admit that health-related disciplines have largely overlooked the lessons learned from other scientific disciplines on how best to persuade behavioral change. What is urgently needed, is research on the system feature level or on the level of categories of system features rather than on the level of the whole system only.

\section{Discussion}

Empirical BCSS research provides a unique opportunity for quantifying measures for system success. This requires explicitly stating the aim of the system, how the success was to be measured, and the extent to which the system succeeded in achieving this measure. It has to be explicitly defined what really takes place through the software system to be able to demonstrate to what extent an outcome/change is really due to the system, or a feature or a set of features in it. Thus, sound ways for defining the systems and their intent clearly are needed. Otherwise, it will be difficult or perhaps even impossible to demonstrate the value of any research results from the BCSS and to translate the lessons learned from the results into related problem and application domains. On the theoretical side, even the relatively well-known persuasion techniques need to be adapted or fine-tuned to match computing specificities.

Yet, in the current research, there is a clear tendency of describing the BCSSs at too general a level [e.g. 13, 14]. When describing a BCSS, a clear description of the persuasion context, i.e. contexts related to use situation, a user him or herself, and the information technology being utilized, is needed. After all, much of the success or failure of an application can often be attributed to the fluent navigation and smooth interaction arising from the technological platform and infrastructure or overall user experience rather than to the specific design of the system. Relying on black-box thinking of software systems - with no actual description of what was implemented and how - is a symptom of a misunderstanding of conducting BCSS research. This black-box thinking of the software systems may even make some of the research results obsolete. The differences between problem domains also are remarkable to the extent that very general claims can be seldom argued for. For instance, in most of the experimental research into persuasive technology users (often students) are regarded as a homogenous mass; more specific information is often limited to gender and age [30]. Yet, deeper understanding of the user segments [71], or perhaps even individual user profiles [72], is important for designing successful BCSSs. Specific target audiences may request different kinds of software features. Just consider the differences between small schoolchildren, tweens, teens, and young adults in comparison to lumping them all together as students. The message and route for persuasion are also often not described at such a level of detail that it would be possible to determine whether a direct or indirect approach actually has been applied and whether that has played a role in the success or failure of the system. Moreover, it should be clearly defined whether one or multiple arguments were presented and what kinds of arguments were presented. It is the abovementioned $\mathrm{O} / \mathrm{C}$ matrix, which can help analyze the intent of the BCSS, whereas the PSD model helps in analyzing the persuasiveness of the BCSS. In rigorous BCSS research these should be used on par with the relevant theories to give meaning for the research results obtained through surveys, studies, experiments and other research attempts. Indeed, to carry out BCSS research one should choose 
(one or more) suitable theories and then analyze the intent of the BCSS and the persuasive potential of the BCSS before proceeding to measuring and explaining the change. Admittedly, space in scientific articles is often too limited to provide very many details about the system itself. For this reason, the actual system descriptions easily become radically shortened or even end-up being cut out from the papers. But those should be included in the articles and/or in their multimedia appendices. Moreover, the field would benefit from a shift in research emphasis from proof of concept approaches into theorizing for BCSS and persuasive systems design. Even if the framework suggested via the PSD model does not define directly the most suitable technologies to be utilized in each project, it helps to recognize such design and implementation related issues that enable to choose viable technological platforms. In similar manner, the power of the O/C matrix is in recognizing key design and research issues rather than providing direct and explicit measures for a project's success.

Quite surprisingly, ethical considerations, in spite of often mentioned, have remained largely unaddressed in BCSS research [30]. Regarding this, many important issues need to be recognized, such as the actual voluntariness for change in using the application and potential ways for abusing the system. There may also be situations where computer-mediated persuasion takes place without the user being aware of it. These 'grey areas' should be carefully considered. All too often the empirical and experimental research does not reveal much about the motives behind the system under study. The designer bias should necessarily be revealed much more clearly.

For a list of open research questions to be tackled in future BCSS research see Table 4. In spite of these many questions, the ultimate question still is, of course, how to measure behavior change through a BCSS. Yes, being able to measure and thus demonstrate the behavior change being caused by an intervening BCSS or in best cases by a specific feature in it is quintessential for determining the success of any of such interventions.

\section{Table 4 Open BCSS research agenda}

\begin{tabular}{|c|c|}
\hline Theoretical basis & $\begin{array}{l}\text { How can we map psychological and behavioral theories within computer and } \\
\text { information science frameworks? } \\
\text { When should a BCSS use a direct and/or indirect persuasion strategy? } \\
\text { What is the role of goal setting in different kinds of BCSSs? How can changes in the } \\
\text { user's goals during the process be supported? } \\
\text { What are the roles of cognition and emotion in BCSSs? } \\
\text { What is the relationship between convincing and persuasion in BCSSs? } \\
\text { What is the difference between persuasiveness and perceived persuasiveness? How } \\
\text { should perceived persuasiveness be measured? } \\
\text { What are the finer differences between problem domains (e.g., reduced energy } \\
\text { consumption vs. overcoming addictions or increased exercising vs. weight } \\
\text { management)? }\end{array}$ \\
\hline $\begin{array}{l}\text { Analysis of the } \\
\text { intended outcome/ } \\
\text { change }\end{array}$ & $\begin{array}{l}\text { What challenges do A-, B- and C-Change pose for carrying out BCSS research? What } \\
\text { are the similarities and differences in measuring C-, B- and A-Changes? What are the } \\
\text { connections between C-, B- and A-Change? How to actually measure C-, B- and A- } \\
\text { Changes? } \\
\text { How do the BCSSs developed for C-, B- and A-Changes differ from each other? How } \\
\text { do the BCSSs developed for R-, A- and F-Outcomes differ from each other? }\end{array}$ \\
\hline $\begin{array}{l}\text { Analysis of the } \\
\text { persuasive potential }\end{array}$ & $\begin{array}{l}\text { How can we build BCSSs in such a manner that they will be unobtrusive with users' } \\
\text { primary tasks? } \\
\text { How can we conduct experiments in such a manner that it will be really possible to } \\
\text { pinpoint a change to have been caused by a BCSS, or even more precisely, by a } \\
\text { specific software feature in it? } \\
\text { Which software features or combinations of software features have the greatest impact } \\
\text { in different settings? } \\
\text { Which modes of interaction are more persuasive than others? How can the fit between } \\
\text { these interaction modes and catering for certain types of behaviors be recognized and } \\
\text { measured? } \\
\text { In general, how do different persuasive features relate to each other? } \\
\text { What are the challenges in the development of persuasive } \\
\text { ecosystems/platforms/systems/services/applications/features? } \\
\text { What is the difference between developing a BCSS as a software system vs. as a } \\
\text { software service (e.g., a mash-up)? }\end{array}$ \\
\hline
\end{tabular}




\begin{tabular}{|l|l|}
\hline \multirow{2}{*}{$\begin{array}{l}\text { Business, ethical, } \\
\text { cultural and other }\end{array}$} & $\begin{array}{l}\text { What challenges result from the requirement for a service to be available 24/7? } \\
\text { How can we cope with it when the technological platform which the BCSS has been } \\
\text { built upon changes dramatically between starting and ending the measurement? }\end{array}$ \\
\hline $\begin{array}{l}\text { How can we recognize and analyze the unintended side-effects of using a BCSS? } \\
\text { How and to what extent should the bias behind a BCSS be explicated? } \\
\text { What are viable business models for BCSSs? } \\
\text { What are the cultural and gender differences in BCSSs? } \\
\text { What other research issues (other than ones relating to the user interface) need to be } \\
\text { tackled? }\end{array}$ \\
\hline
\end{tabular}

As can be seen from Table 4, many research questions remain to be addressed and multiple research methods and approaches may be applied for studying the behavior change support systems. Even if ample research efforts have already been conducted thus far, we are still in the very early steps of research into BCSS. Observing users and monitoring their social interactions, use of living labs, open innovation and crowdsourcing methods, use of design research methods, study of user experiences, experimenting with emotions and building affective computing prototypes all provide interesting opportunities for research. Eye-tracking and measurements based on heart-rate and other physical or bodily functions [69] may help understanding, for example, users' subliminal behaviors, and fMRI (functional Magnetic Resonance Imaging) provides an interesting method and avenue for future research. Indeed, many kinds of research experiments can be done, but in particular behavioral measurements in natural environments would be desirable.

\section{Conclusions}

In spite of its very rapid development the emerging area of behavior change support systems is still in its infancy. It is challenging to measure actual behaviors, and even more so changes in behavior which is the goal of these systems. The major weakness in research into BCSSs thus far has been that the information systems, which are the core of the whole phenomena, all too often have been described in such a coarse manner that it has been very difficult to demonstrate what actually caused a change, if any, or to generalize any of the findings. This article has proposed methods for understanding the prerequisites for being able to actually measure these systems. The concept of behavior change support system was suggested as a key construct for research into persuasion, influence, nudge and coercion. The O/C matrix and the PSD model were suggested as vehicles to better frame research and design activities. The article also suggested that a change in complying, a behavior change, and an attitude change (C-, B- or A-Change) constitute the archetypes of a behavioral change. Change in itself is either of a forming, altering or reinforcing outcome (F-, Aor R-Outcome). These methodological aids can be used in a variety of settings ranging from evaluating software specifications in the early stages of systems development to studying fullfledged commercial systems.

\section{References}

[1] Kraft, P., Drozd, F. and Olsen, E. ePsychology: Designing theory-based health promotion interventions. Communications of the Association for Information Systems: Vol. 24, Article 24, 2009.

[2] Strecher, V. Internet methods for delivering behavioral and health-related interventions (eHealth). Annual Review of Clinical Psychology, 3, 2007, 53-76.

[3] Midden, C., Ham. J. Using negative and positive social feedback from a robotic agent to save energy. ACM International Conference Proceeding Series, Vol. 350, Proceedings of the Fourth International Conference on Persuasive Technology, Claremont, CA, USA, April 26-29, 2009.

[4] Harjumaa, M., Segerståhl, K., and Oinas-Kukkonen, H. Understanding Persuasive System Functionality in Practice: a Field Trial of Polar FT60. ACM International Conference Proceeding Series, Vol. 350, Proc. of the Fourth Intl. Conf. on Persuasive Technology, Claremont, CA, USA, April 26-29, 2009.

[5] Oinas-Kukkonen, H., Harjumaa, M. Persuasive systems design: Key issues, process model, and system features. Communications of the Association for Information Systems, 24, Article 28, 2009, 485-500. 
[6] Fishbein, M., \& Ajzen, I. Belief, attitude, intention, and behavior: An introduction to theory and research. Addison-Wesley, Reading, MA, 1975.

[7] Ajzen, I. The theory of planned behavior. Organizational Behavior and Human Decision Processes, 50(2), 1991, 179-211.

[8] Bandura, A. Self-Efficacy: Toward a unifying theory of behavioral change. Psychology Review, 84, 1977, 191-215.

[9] Bandura, A. (1986) Social foundations of thought and action: A social cognitive theory. Prentice-Hall, Englewood Cliffs, NJ.

[10] Petty, R.E. and Cacioppo, J.T. Communication and persuasion: Central and peripheral routes to attitude change. Springer, New York, 1986.

[11] Lehto T \& Oinas-Kukkonen H (2009) The Persuasiveness of Web-Based Alcohol Interventions: A qualitative evaluation. IFIP Advances in Information and Communication Technology, Software Services for e-Business and e-Society, Vol. 305, pp. 316-327, 2009.

[12] Bensley RJ, Brusk JJ, Rivas J. (2010) Key principles in internet-based weight management systems. Am J Health Behav 2010;34(2):206-213.

[13] Neve, M., Morgan, P.J., Collins, C.E. (2011) Weight Change in a Commercial Web-Based Weight Loss Program and its Association With Website Use: Cohort Study. J Med Internet Res 2011;13(4):e83.

[14] Lehto, T \& Oinas-Kukkonen H (2011) Persuasive Features in Web-Based Alcohol and Smoking Interventions: A Systematic Review of the Literature. Journal of Medical Internet Research, 13(3), e46.

[15] Oinas-Kukkonen, H. Discipline of Information Systems: A Natural Strategic Alliance for Web Science. Proc. of the Second Intl. Web Science Conference (WebSci 10), Raleigh, NC, US, April 26-27, 2010.

[16] Davis, F.D. Perceived usefulness, perceived ease of use, and user acceptance of information technology. MIS Quarterly, 13(3), 1989, 319-339.

[17] Venkatesh, V., Morris, M., Davis, G.B and Davis, F.D. User acceptance of information technology: Toward a unified view. MIS Quarterly, 27(3), 2003, 425-478.

[18] Festinger, L.A. Theory of cognitive dissonance. Stanford University Press, Stanford, CA, 1957

[19] Locke, E.A. and G.P. Latham (2002) "Building a Practically Useful Theory of Goal Setting and Task Motivation”, American Psychologist (57)9, pp. 705-717.

[20] Compeau, D.R., and Higgins, C.A. Computer self-efficacy: Development of a measure and initial test. MIS Quarterly, 19(2), 1995b, 189-211.

[21] Bandura, A. (1994). Self-efficacy. In V. S. Ramachaudran (Ed.), Encyclopedia of human behavior (Vol. 4, pp. 71-81). New York: Academic Press.

[22] Rosenstock, I.M. (1974) The health belief model and preventive health behavior. Health Education Monographs.

[23]Bish, A., Sutton, S., and Golombok, S. (2000). Predicting uptake of a routine cervical smear test: A comparison of the health belief model and the theory of planned behaviour. Psychology \& Health, 15(1), 35-50.

[24] Prochaska, J.O. and DiClemente, C.C. (1994) The transtheoretical approach: Crossing traditional boundaries of therapy, Krieger Pub Co.

[25] Prochaska J.O., and W.F. Velicer (1997) Behavior Change: The Transtheoretical Model of Health Behavior Change. American Journal of Health Promotion, Volume 12, Issue 1 September.

[26] Bensley, R.J., N. Mercer, J.J. Brusk, et al. (2004) The eHealth behavior management model: A stagebased approach to behavior change and management. Preventing Chronic Disease, Public Health Research, Practice, and Policy. 1(4):1-13.

[27] Fishbein, M. (2000) The role of theory in HIV prevention. AIDS Care. 12, 273-278.

[28] Bandura, A. (2004) Health promotion by social cognitive means. Health Education \& Behavior, Vol. 31, No. 2, 143-164.

[29] Lerbinger, O. (1972) Designs for persuasive communication, New Jersey: Englewood Cliffs.

[30] Tørning, K. and Oinas-Kukkonen, H. Persuasive System Design: State of Art and Future Directions. ACM International Conference Proceeding Series, Vol. 350, Proceedings of the Fourth International Conference on Persuasive Technology, Claremont, CA, USA, April 26-29, 2009.

[31]Xiao, B and Benbasat, I (2011) "Product-Related Deception in E-Commerce: A Theoretical Perspective," MIS Quarterly, (35: 1) pp.169-195.

[32] Miller, G.R. (2002) “On being persuaded: Some basic distinctions” in Dillard J.P. and M. Pfau (eds.) The Persuasion Handbook: Developments in Theory and Practice. Thousand Oaks, California: Sage Publications, pp. 3-16. 
[33] Fogg, B.J. Persuasive technologies - Introduction. Communications of the ACM, 42(5), May 1999, 2629.

[34] Picard, R. Affective Computing. MIT Press, Cambridge, MA, 1997.

[35] Atkinson B. Captology - A critical review. Lecture Notes in Computer Science, Springer, 2006, 171182.

[36] Fogg, B.J. Persuasive technology: Using computers to change what we think and do. Morgan Kaufmann Publishers, San Francisco, 2003.

[37] Bogost I. Persuasive games: The expressive power of videogames, The MIT Press, Cambridge, MA, 2007.

[38] Oinas-Kukkonen, H., Harjumaa, M. A Systematic Framework for Designing and Evaluating Persuasive Systems. Lecture Notes in Computer Science, Vol. 5033, pp. pp. 164-176. Springer, Heidelberg (2008).

[39] Forget, A., Chiasson, S., van Oorschot, P.C. and Biddle, R. Persuasion for stronger passwords: Motivation and pilot study. Lecture Notes in Computer Science, Vol. 5033, Springer, 140-150.

[40] Obermair, C., Reitberger, W., Meschtscherjakov, A., Lankes, M. and Tscheligi, M. perFrames: Persuasive picture frames for proper posture. Lecture Notes in Computer Science, Vol. 5033, Springer, 2008, 128-139.

[41] Chi, P., Chen, J., Chu, H., \& Lo, J. Enabling calorie-aware cooking in a smart kitchen. Lecture Notes in Computer Science, Vol. 5033, Springer, 2008, 116-127.

[42] Parmar, V., Keyson, D. and de Bont, C. Persuasive technology to shape social beliefs: A case of persuasive health information systems for rural women in India. Communications of the Association for Information Systems, Vol. 24, Article 25, 2009.

[43] Munson SA, Lauterbach D, Newman MW, Resnick P (2010) Happier Together: Integrating a Wellness Application into a Social Network Site. Lecture Notes in Computer Science, Persuasive Technology, Volume 6137, pp. 27-39.

[44] Stibe A., Oinas-Kukkonen H. (2012) Comparative Analysis of Recognition and Competition as Features of Social Influence Using Twitter. Lecture Notes in Computer Science, Persuasive 2012, Linköping, Sweden.

[45] Oinas-Kukkonen H \& Harjumaa M (2008) Towards Deeper Understanding of Persuasion in Software and Information Systems. The First International Conference on Advances in Human-Computer Interaction (ACHI '2008), Sainte Luce, Martinique, February 10-15, 2008, ISBN 978-0-7695-3086-4, pp. 200-205, Best Paper Award.

[46] Benbasat, I (2010) "HCI Research: Future Challenges and Directions,” AIS Transactions on HumanComputer Interaction, (2) 2, pp. 16-21

[47] Jenkin TA, Webster J, McShanea L (2011) An agenda for 'Green’ information technology and systems research. Information and Organization. Volume 21, Issue 1, January 2011, Pages 17-40.

[48] Derrick, DC.; Jenkins, JL.; and Nunamaker, Jr., JF. (2011) "Design Principles for Special Purpose, Embodied, Conversational Intelligence with Environmental Sensors (SPECIES) Agents," AIS $\begin{array}{lllll}\text { Transactions on Human-Computer Interaction (3) 2, pp. } & \text { 62-81 }\end{array}$ Available at: http://aisel.aisnet.org/thci/vol3/iss2/2

[49] Cugelman B, Thelwall M, Dawes P (2011) Online Interventions for Social Marketing Health Behavior Change Campaigns: A Meta-Analysis of Psychological Architectures and Adherence Factors. J Med Internet Res 2011 (Feb 14); 13(1):e17.

[50] Young MM (2010) Twitter Me: Using Micro-blogging to Motivate Teenagers to Exercise. Global Perspectives on Design Science Research. Lecture Notes in Computer Science, Volume 6105, 439-448,.

[51]Li H and Chatterjee S (2010) Designing Effective Persuasive Systems Utilizing the Power of Entanglement: Communication Channel, Strategy and Affect. Lecture Notes for Computer Science, Persuasive, Vol. 6137, 2010.

[52] Yap M, Jorm A, Bazley R, Kelly C, Ryan S, and Lubman D (2011) Web-based parenting program to prevent adolescent alcohol misuse: rationale and development. Australasian Psychiatry. August 2011, Vol. 19, No. 4 , Pages 339-344.

[53] Räisänen T, Lehto T \& Oinas-Kukkonen H (2010) Practical Findings from Applying the PSD Model for Evaluating Software Design Specifications. Lecture Notes in Computer Science, Persuasive, Vol. 6137, pp. 185-192, 2010, Springer-Verlag.

[54] Segerståhl K, Kotro T and Väänänen-Vainio-Mattila K (2010) Pitfalls in Persuasion: How Do Users Experience Persuasive Techniques in a Web Service? Lecture Notes in Computer Science, Volume 6137, Persuasive Technology, pp. 211-222.

[55] Kelders S.M., Kok R.N., Ossebaard H.C., and Van Gemert-Pijnen J.E.W.C. (2011) Technology and Adherence in Web-based Interventions for Weight Control: A Systematic Review. ACM International 
Conference Proceeding Series, Vol, Proceedings of the Sixth International Conference on Persuasive Technology, Columbus, OH, USA, June 2-5, 2011.

[56] Davis J (2010) Generating Directions for Persuasive Technology Design with the Inspiration Card Workshop. Lecture Notes in Computer Science, Volume 6137, Persuasive Technology, pp. 262-273..

[57] Lehto T \& Oinas-Kukkonen H (2010) Persuasive Features in Six Weight Loss Websites: A Qualitative Evaluation. Lecture Notes for Computer Science, Persuasive, Vol. 6137, 2010.

[58] Wiafe, I; Nakata, K; Moran, S; and Gulliver, S (2011) Considering user attitude and behaviour in persuasive systems design:; The 3D-RAB Model. In: Proceedings of the 19th European Conference on Information Systems (ECIS 2011). http://aisel.aisnet.org/ecis2011/186

[59] Yetim, F (2011) A Set of critical heuristics for value sensitive designers and users of persuasive systems. In: Proceedings of the 19th European Conference on Information Systems (ECIS 2011). http://aisel.aisnet.org/ecis2011/185

[60] Fichman, R.G., Kohli, R., Krishnan, R. (2011) Editorial Overview-The Role of Information Systems in Healthcare: Current Research and Future Trends. Information Systems Research, September, 22(3), 419428.

[61] Cassell, M.M., C. Jackson, and B. Cheuvront (1998) "Health Communication on the Internet: An Effective Channel for Health Behavior Change”, Journal of Health Communication, (3)1, pp. 71-79.

[62] Kelley, Helen; Chiasson, Mike; Downey, Angela; and Pacaud, Danièle (2011) "The Clinical Impact of eHealth on the Self-Management of Diabetes: A Double Adoption Perspective," Journal of the Association for Information Systems: Vol. 12: Iss. 3, Article 4. Available at: http://aisel.aisnet.org/jais/vol12/iss3/4

[63] Ritterband, L. M., Gonder-Frederick, L. A., Cox, D. J., Clifton, A. D., West, R. W., \& Borowitz, S. M. (2003). Internet interventions: In review, in use, and into the future. Professional Psychology Research and Practice, 34(5), 527-534.

[64] Wantland, D. J., Portillo, C. J., Holzemer, W. L., Slaughter, R., \& McGhee, E. M. (2004). The effectiveness of web-based vs. non-web-based interventions: A meta-analysis of behavioral change outcomes. Journal of Medical Internet Research, 6(4)

[65] Bock, B., A. Graham, C. Sciamanna, J. Krishnamoorthy, and J. Whiteley et al. (2004) Smoking cessation treatment on the Internet: content, quality, and usability. Nicotine Tob. Res., 6, 2, 207-219.

[66] Doshi, A., K. Patrick, J.F. Sallis, and K. Calfas (2003) Evaluation of physical activity web sites for use of behavior change theories. Annals of Behavioral Medicine, 25(2), 105.

[67] Portnoy, D. B., Scott-Sheldon, L. A. J., Johnson, B. T., \& Carey, M. P. (2008). Computer-delivered interventions for health promotion and behavioral risk reduction: A meta-analysis of 75 randomized controlled trials, 1988-2007. Preventive Medicine.

[68] Duffett-Leger, L., B. Paterson, and W. Albert (2008) Optimizing Health Outcomes by Integrating Health Behavior and Communication Theories in the Development of e-Health Promotion Interventions, eHealth International, Vol. 4, No. 2, 23-33.

[69] Enwald HPK., Niemelä RM, Keinänen-Kiukaanniemi S, Leppäluoto J, Jämsä T, Herzig K-H, OinasKukkonen H, Huotari M-L (2011) Human information behaviour and physiological measurements as a basis to tailor health information. An explorative study in a physical activity intervention among prediabetic individuals in Northern Finland. Health Information \& Libraries Journal, article in press.

[70]Fogg, B.J, (2009) The Behavior Grid: 35 ways behavior can change. ACM International Conference Proceeding Series, Vol. 350, Proceedings of the Fourth International Conference on Persuasive Technology, Claremont, CA, USA, April 26-29, 2009.

[71] Berkovsky S., Freyne J., Oinas-Kukkonen H. (2012) Influencing Individually: Fusing Personalization and Persuasion. ACM Transactions on Intelligent Interactive Systems, forthcoming.

[72] Kaptein M., De Ruyter B., Markopoulos P., and Aarts E. (2012) Adaptive Persuasive Systems: A Study of Tailored Persuasive Text Messages to Reduce Snacking. ACM Transactions on Intelligent Interactive Systems, forthcoming. 